\title{
Effect of varying the pressurisation rate during noninvasive pressure support ventilation
}

\author{
G. Prinianakis*, M. Delmastro", A. Carlucci", P. Ceriana\#, S. Nava\#
}

Effect of varying the pressurisation rate during noninvasive pressure support ventilation. G. Prinianakis, M. Delmastro, A. Carlucci, P. Ceriana, S. Nava. (C) ERS Journals Ltd 2004.

ABSTRACT: The aim of the study was to assess the effects of varying the pressurisation rate during noninvasive pressure support ventilation on patients' breathing pattern, inspiratory effort, arterial blood gases, tolerance to ventilation and amount of air leakage.

A total of 15 chronic obstructive pulmonary disease patients recovering from an acute episode of hypercapnic acute respiratory failure were studied during four randomised trials with different levels of pressurisation rate.

No significant changes were observed in breathing pattern and arterial blood gases between the different runs. The pressure time product of the diaphragm, an estimate of its metabolic consumption, was significantly lower with all pressurisation rates than with spontaneous breathing, but was significantly lowest with the fastest rate. However, air leak, assessed by the ratio between expired and inspired tidal volumes, increased and the patients' tolerance of ventilation, measured using a standardised scale, was significantly poorer with the fastest pressurisation rate.

In chronic obstructive pulmonary disease patients recovering from an episode of acute hypercapnic respiratory failure and ventilated with noninvasive pressure support ventilation, different pressurisation rates resulted in different reductions in the pressure time product of the diaphragm; this reduction was greater with the fastest rate, but was accompanied by significant air leaks and poor tolerance.

Eur Respir J 2004; 23: 314-320.
*Intensive Care Unit Heraklion Hospital, Crete, Greece and ${ }^{\#}$ Respiratory Intensive Care Unit, Fondazione S. Maugeri, Istituto Ricovero e Cura Carattere Scientifico, Istituto Scientifico di Pavia, Pavia, Italy.

Correspondence: S. Nava

Respiratory Unit

Fondazione S. Maugeri

Via Ferrata 8

27100 Pavia

Italia

Fax: 390382592075

E-mail: snava@fsm.it

Keywords: Chronic obstructive pulmonary disease

initial inspiratory flow

noninvasive pressure support ventilation ventilator settings

Received: January 292003

Accepted after revision: September 102003
During assisted mechanical ventilation, changes in ventilatory settings (i.e. levels of inspiratory and expiratory assistance, mechanical inflation time, and inspiratory flow) are commonly used in order to achieve better synchrony between the patient and ventilator, less dynamic hyperinflation, reduced work of breathing and more efficient gas exchange [1-4]. This holds particularly true in patients ventilated noninvasively in whom the success of noninvasive ventilation (NIV) largely depends on the acceptance and compliance of the patient, and these are likely to be associated with the way that this method of ventilation is administered. Pressure modes of ventilation (i.e. flow or time cycled) are the most clinically used assisted mode of NIV [5]. Pressure support ventilation (PSV), for example, applies a constant level of positive airway pressure during spontaneous inspiratory efforts; the patient is not a "passive" part of the process, but may respond to the changes in ventilator settings via chemical, mechanoreceptor reflex and behavioural feedback systems [6-8].

It was shown, in intubated patients with chronic obstructive pulmonary disease (COPD) or restrictive diseases, that a reduction of the initial flow rate, obtained by varying the inspiratory pressurisation rate, modified the breathing pattern, progressively increased the work of breathing and reduced mechanical output (i.e. tidal volume $(V \mathrm{~T})$ ) [9-12]. However, the results of these studies cannot automatically be extrapolated to patients undergoing NIV, in whom abrupt changes in the pressurisation rate may interfere with patients' tolerance of the ventilation and the amount of air leakage. Therefore, the present study aimed to determine, in patients with COPD recovering from an episode of acute respiratory failure and ventilated noninvasively, the acute response induced by varying the pressurisation rate on breathing pattern, diaphragmatic function, gas exchange, the amount of air leakage and patient's tolerance.

\section{Materials and methods}

A total of 15 COPD patients were admitted to the Respiratory Intensive Care Unit at the Istituto Scientifico di Pavia, Italy, for management of acute hypercapnic respiratory failure due to COPD [13]. At the time of the study all the patients were haemodynamically stable without the use of vasoactive drugs and were recovering from the acute phase of their disease. The patients' characteristics, the ventilatory settings at the time of the study, and the arterial blood gases at the time of exacerbation necessitating NIV are shown in table 1. All the patients were ventilated with the same intensive care unit (ICU) ventilator (Cesar, Taema, France) and with a full face mask, tailored to each patient's facial features. Great care was taken by the respiratory therapists in charge of NIV, and blinded to the protocol, to avoid any possible air leaks. The masks were adjusted at the beginning of each trial. The settings of the ventilator were determined by the primary physician, who was unaware of the aim of the study, and remained constant throughout the different experimental trials.

In the Respiratory Intensive Care Unit the clinical settings 
Table 1.-Patients' characteristics and baseline ventilator settings at the beginning of the experimental trial

\begin{tabular}{|c|c|c|c|c|c|c|c|c|c|}
\hline $\begin{array}{l}\text { Patient } \\
\text { no. }\end{array}$ & $\begin{array}{l}\text { Age } \\
\text { yrs }\end{array}$ & $\mathrm{pH}$ & $\begin{array}{c}\mathrm{Pa}, \mathrm{CO}_{2} \\
\mathrm{mmHg}\end{array}$ & $P \mathrm{a}, \mathrm{O}_{2} / F \mathrm{I}, \mathrm{O}_{2}$ & $\begin{array}{l}\text { FEV1 } \\
\% \text { pred }\end{array}$ & $\underset{\%}{\mathrm{FEV} 1 / \mathrm{FVC}}$ & $\begin{array}{c}\mathrm{PS} \\
\mathrm{cmH}_{2} \mathrm{O}\end{array}$ & $\begin{array}{c}\text { PEEPext } \\
\mathrm{cmH}_{2} \mathrm{O}\end{array}$ & $\begin{array}{c}\text { Initial } \\
\text { pressurisation } \\
\text { rate } \mathrm{cmH}_{2} \mathrm{O} \cdot \mathrm{s}^{-1}\end{array}$ \\
\hline 1 & 74 & 7.31 & 94.30 & 264.00 & 21.00 & 18.00 & 14.00 & 2.00 & 80.00 \\
\hline 2 & 65 & 7.28 & 82.70 & 258.00 & 43.00 & 33.00 & 15.00 & 4.00 & 120.00 \\
\hline 3 & 83 & 7.32 & 77.30 & 190.00 & 18.00 & 25.00 & 14.00 & 2.00 & 60.00 \\
\hline 4 & 56 & 7.34 & 60.70 & 275.00 & 22.00 & 19.00 & 18.00 & 4.00 & 120.00 \\
\hline 5 & 74 & 7.30 & 63.60 & 156.00 & NA & NA & 16.00 & 4.00 & 60.00 \\
\hline 6 & 78 & 7.25 & 71.50 & 128.00 & 33.00 & 22.00 & 12.00 & 4.00 & 60.00 \\
\hline 7 & 67 & 7.33 & 56.70 & 249.00 & NA & NA & 15.00 & 2.00 & 80.00 \\
\hline 8 & 68 & 7.29 & 71.70 & 281.00 & NA & NA & 18.00 & 4.00 & 100.00 \\
\hline 9 & 80 & 7.21 & 93.50 & 222.00 & 28.00 & 37.00 & 14.00 & 5.00 & 58.00 \\
\hline 10 & 77 & 7.16 & 104.20 & 146.00 & 24.00 & 41.00 & 22.00 & 6.00 & 60.00 \\
\hline 11 & 81 & 7.33 & 57.2 & 189.00 & 17.00 & 62.00 & 12.00 & 2.00 & 80.00 \\
\hline 12 & 62 & 7.32 & 83.00 & 219.00 & 13.00 & 19.00 & 13.00 & 3.00 & 30.00 \\
\hline 13 & 71 & 7.34 & 81.00 & 237.00 & NA & NA & 14.00 & 4.00 & 120.00 \\
\hline 14 & 70 & 7.32 & 53.30 & 243.00 & 42.00 & 44.00 & 14.00 & 4.00 & 80.00 \\
\hline 15 & 61 & 7.29 & 69.5 & 240.00 & 15.00 & 21.00 & 18.00 & 4.00 & 50.00 \\
\hline Mean \pm SD & $7 \pm 7.9$ & $7.32 \pm 0.01$ & $68.8 \pm 14$ & $226 \pm 22.5$ & $21.8 \pm 14$ & $36.5 \pm 20.4$ & $14.2 \pm 2$ & $3.4 \pm 1$ & $77.5 \pm 37$ \\
\hline
\end{tabular}

Arterial blood gases were taken at the time of the episode of acute respiratory failure, necessitating noninvasive ventilation. $P$ a $, \mathrm{CO}_{2}:$ partial pressure of arterial carbon dioxide oxygen; $\mathrm{Pa}, \mathrm{O}_{2}$ : partial pressure of arterial oxygen; $\mathrm{FI}, \mathrm{O}_{2}$ : fractional concentration of oxygen; FEV1: forced expiratory volume in one second; $\%$ pred: \% predicted; FVC: forced vital capacity; PS: pressure support level; PEEPext: external positive end-expiratory pressure; NA: not available. $\mathrm{kPa}=\mathrm{mmHg} \times 0.133$.

of PSV are based on simple clinical parameters such as the patient's comfort (i.e. respiratory rate $<25$ breaths $\cdot \mathrm{min}^{-1}$ and no evident sign of wasted respiratory efforts on the flow trace [14], expired $V \mathrm{~T}(V$ Texp$)>6 \mathrm{~mL} \cdot \mathrm{kg}^{-1}$ and $<10 \mathrm{~mL} \cdot \mathrm{kg}^{-1}$ and satisfactory gas exchange (i.e. arterial oxygen saturation $\left(\mathrm{Sa}_{\mathrm{a}} \mathrm{O}_{2}\right)>90 \%$, with $\left.\mathrm{pH}>7.35\right)$. The inspiratory trigger was set at $-0.5 \mathrm{cmH}_{2} \mathrm{O}$, while the initial pressurisation rate was adjusted according to subjective comfort at the beginning of the ventilation and remained unchanged until the beginning of the experimental trial. The fractional concentration of oxygen was such to achieve an oxygen saturation $\left(\mathrm{Sa}, \mathrm{O}_{2}\right)>90 \%$. The study was approved by the Local Ethics Committee and oral informed consent was obtained from the patients.

\section{Measurements}

Arterial blood gases were measured in blood taken from a radial artery in 10 patients. Flow at the airway opening was measured with a heated pneumotachograph (Hans-Rudolf 3700; Kansas City, KS, USA) and a differential pressure transducer (Honeywell, Freeport, IL, USA; $\pm 300 \mathrm{~cm} \mathrm{H} \mathrm{H}_{2} \mathrm{O}$ ) placed between the mask and the Y-piece of the ventilator. Tidal volume (VTinsp) was obtained by integration of the flow. The breathing pattern was measured from the flow signal. VTexp was used for data analysis. Inspiratory time $(t \mathrm{I})$, expiratory time $(t \mathrm{E})$ and total respiratory time were calculated on the flow trace. The ratio of expired volume over $V$ Tinsp to quantify the amount of air-leaks was also measured [15].

Airway pressure (Honeywell; $\pm 300 \mathrm{~cm} \mathrm{H}_{2} \mathrm{O}$ ) was measured from a side port between the pneumotachograph and the face mask. Oesophageal and gastric pressures were measured with a balloon-catheter system. To this aim, an oesophageal balloon was positioned at the lower third of the oesophagus, filled with $0.5 \mathrm{~mL}$ of air and a gastric balloon filled with $1 \mathrm{~mL}$ of air. The proper position of the balloon was verified using the occlusion test [16]. Transdiaphragmatic pressure $(P \mathrm{di})$ was calculated as the difference between gastric $(P$ ga $)$ and oesophageal (Poes) pressure.

The pressure time integrals of the diaphragm (PTPdi) and the other inspiratory muscles (PTPoes) were calculated per breath and per minute [1]. The ratio between the neural $t \mathrm{I}$ over the mechanical inspiratory time ( $t$ Ivent) was calculated
[17]. The $t$ I was recorded from the point of rapid decline in $P$ oes to the lowest point in $P$ oes, while the $t$ Ivent was calculated on the flow trace from the onset of the inspiratory flow to the zero flow crossing. Expiratory muscle recruitment during the different trials was assessed by measuring the rise in $P$ ga during expiration from its end-inspiratory level to the maximum at end-expiration [18, 19]. The dynamic intrinsic positive end-expiratory pressure (PEEPi,dyn) was obtained from the $P$ di signal, as the value of $P$ di at the moment of zero flow [20]. Figure 1 shows the methods of measuring $t \mathrm{I}$, mechanical inspiratory time, and PEEPi,dyn. The number of so-called wasted or ineffective efforts, an index of patient/ ventilator mismatching, was also calculated as previously described [14].

The patient's tolerance to ventilation was evaluated on a visual analogue scale. This scale has been used and validated in previous studies and has five scores: 1) bad; 2) poor; 3) sufficient; 4) good; and 5) very good [21]. The patients were asked by the respiratory therapist to answer the following

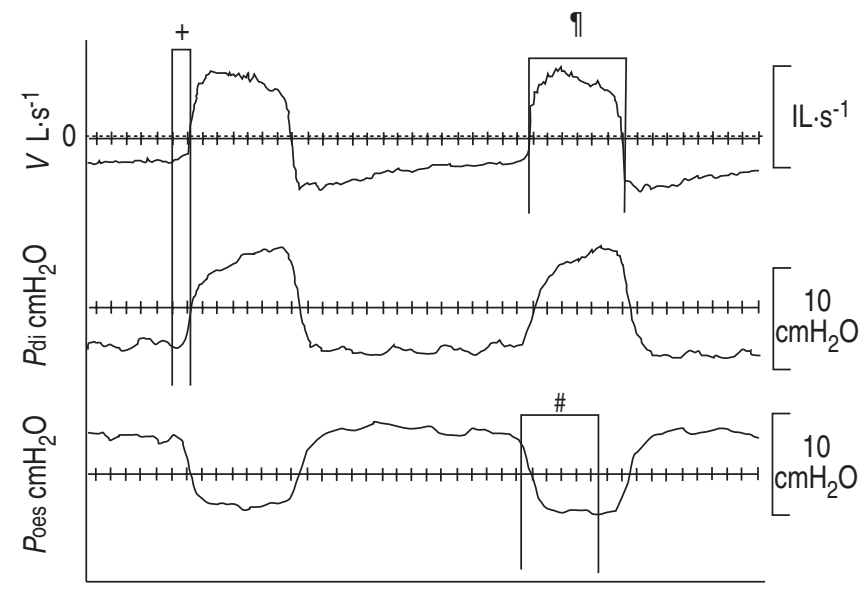

Fig. 1.- Tracings obtained in a representative patient, and illustrating the methods of calculation of the neural inspiratory time $\left({ }^{\#}\right)$, the mechanical inspiratory time $\left({ }^{\sigma}\right)$, and the dynamic intrinsic positive end-expiratory pressure $\left({ }^{+}\right)$. V: flow; $P$ di: transdiaphragmatic pressure; $P$ oes: oesophageal pressure. 
question: "How do you feel your breathing is at this moment". For each condition tested, the patient placed a finger on the number that best represented the intensity of their dyspnoea.

\section{Protocol}

The patients were studied in a semirecumbent position in

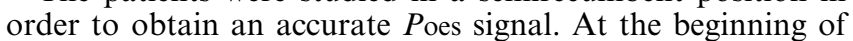
the trial the patients were asked to breath for a few minutes (between 5 and 10) without any ventilatory assistance (baseline recordings). The physiological data were recorded during four randomised trials, each with different pressurisation rates over $20 \mathrm{~min}$, separated by a return to spontaneous breathing for $10 \mathrm{~min}$. The randomisation of the trials was obtained by a computerised program, developed ad hoc, in order to distribute the sequence evenly. The Cesar ventilator offers the option of modulating the pressurisation rate according to the gradient chosen $\left(\mathrm{cmH}_{2} \mathrm{O} \cdot \mathrm{s}^{-1}\right)$ and the patient's inspiratory activity, so that a pressure plateau is reached after a variable time. Inspiration is pressure triggered and the inspiratory pressure ceases when the flow falls to $<5 \mathrm{~L} \cdot \mathrm{s}^{-1}$. In a preliminary pilot study performed on four patients the physiological changes (without the use of the catheter/balloon system) induced by six different pressurisation rates were assessed. The level of $150 \mathrm{cmH} \mathrm{H}_{2} \mathrm{O} \cdot \mathrm{s}^{-1}$ produced a comparable amount of air leaks and discomfort to the patients, as did the level of $200 \mathrm{cmH}_{2} \mathrm{O} \cdot \mathrm{s}^{-1}$. Therefore, the slowest $\left(30 \mathrm{cmH}_{2} \mathrm{O} \cdot \mathrm{s}^{-1}\right)$ and fastest $\left(200 \mathrm{cmH}_{2} \mathrm{O} \cdot \mathrm{s}^{-1}\right)$ pressurisation rates allowed by the Cesar ventilator and two intermediate levels $\left(80 \mathrm{cmH}_{2} \mathrm{O} \cdot \mathrm{s}^{-1}\right.$ and $120 \mathrm{cmH} \mathrm{CH}_{2} \cdot \mathrm{s}^{-1}$ ) were chosen for analysis.

Data obtained from the average of $3 \mathrm{~min}$ of recordings (usually the last three), were considered for analysis. At the end of each trial the patient's comfort of breathing and arterial blood gases were also recorded. All signals were collected using a personal computer equipped with an A/D board, and stored at a sampling rate of $100 \mathrm{~Hz}$.

Results are presented as mean \pm SD for continuous variables, as frequency or percentage for the nominal variables and as median (quartiles or range) for the ordinal variables. Comparisons for each sequence and each continuous variable were performed with one-way analysis of variance for repeated measures. Post hoc comparisons between sequences were performed by using the Duncan's test.

To compare repeated measures for an ordinal variable (patient tolerance) the Friedman test was used, while internal comparisons were performed using a nonparametrical test for multiple post hoc comparisons. All tests were two-sided. A p-value $<0.05$ was considered statistically significant.

\section{Results}

One patient did not tolerate the gastro-oesophageal catheter/ balloon system for the whole duration of the experiment so data on respiratory muscle function were analysed in 14 patients. One patient was unable to understand the scale of tolerance of ventilation so that this analysis, also, was performed on 14 patients.

Table 2 illustrates that no significant changes were found in arterial blood gases during the different trials.

Table 3 shows the breathing patterns and respiratory muscle function with the different pressurisation rates. Expiratory $V \mathrm{~T}$ was significantly lower during spontaneous breathing than during NIV. No significant differences were observed between the different trials of ventilation, except for the $t \mathrm{I} / t$ Ivent ratio and for the peak inspiratory flow that were significantly different, with the fastest rate compared to $30 \mathrm{cmH}_{2} \mathrm{O} \cdot \mathrm{s}^{-1}$.

The fastest pressurisation rate was associated with a significantly higher percentage of air leaks, as depicted by the ratio between expiratory $V \mathrm{~T}(V \mathrm{Texp})$ and $V$ Tinsp $(V \mathrm{Texp} / V$ Tinsp $0.88 \pm 0.13$ for $30 \mathrm{cmH}_{2} \mathrm{O} \cdot \mathrm{s}^{-1}, 0.86 \pm 013$ for $80,0.86 \pm 0.13$ for 120 and $0.79 \pm 0.12$ for $200 ; p<0.01$ for 30 versus 200 ). Individual values of air leaks for different levels of pressurisation rate are illustrated in figure 2 .

The $P$ di, the energy expenditure of the diaphragm (PTPdi) and that of the inspiratory muscle (PTPoes), decrease significantly from those during spontaneous breathing, with the most pronounced decrease being observed when the pressurisation rate increased.

The rise in $P$ ga during expiration from its end-inspiratory level to the maximum at end-expiration $[18,19]$, was minimal in most of the patients, even with the fastest pressurisation rate, so that no statistically significant difference was observed during the different trials. An original record of one typical patient is shown in figure 3 .

Histograms showing the tolerance scores for each pressurisation rate are depicted in figure 4. The fastest rate $\left(200 \mathrm{cmH}_{2} \mathrm{O}\right)$ was the significantly $(\mathrm{p}<0.05)$ worst accepted, whereas no significant difference was found between the other initial flows. No significant statistical correlation was also found between the PSV levels and the pressurisation rates that provided the best comfort.

Patient/ventilator mismatching, as assessed by the number of ineffective efforts, was detected in only one patient during the 80 and $120 \mathrm{cmH}_{2} \mathrm{O} \cdot \mathrm{s}^{-1}$ trials.

\section{Discussion}

During noninvasive PSV in COPD patients recovering from a severe episode of acute respiratory failure, setting a very fast pressurisation rate produced significantly less diaphragm effort and energy expenditure than lower rates without significant changes in arterial blood gases or breathing pattern. However, the main findings of the current study were that these favourable changes were accompanied by a poor tolerance to ventilation and increased air leakage.

Table 2. - Patients' blood gases values for each trial

\begin{tabular}{|c|c|c|c|c|c|}
\hline & \multicolumn{4}{|c|}{ Pressurisation rate } & \multirow[t]{2}{*}{$\mathrm{p}$-value } \\
\hline & $30 \mathrm{cmH}_{2} \mathrm{O} \cdot \mathrm{s}^{-1}$ & $80 \mathrm{cmH}_{2} \mathrm{O} \cdot \mathrm{s}^{-1}$ & $120 \mathrm{cmH}_{2} \mathrm{O} \cdot \mathrm{s}^{-1}$ & $200 \mathrm{cmH}_{2} \mathrm{O} \cdot \mathrm{s}^{-1}$ & \\
\hline $\mathrm{pH} \mathrm{mmHg}$ & $7.41 \pm 0.035$ & $7.41 \pm 0.028$ & $7.42 \pm 0.036$ & $7.42 \pm 0.039$ & NS \\
\hline $\mathrm{Pa}, \mathrm{O}_{2} \mathrm{mmHg}$ & $86.81 \pm 11.0$ & $88.3 \pm 20.4$ & $88.3 \pm 20.4$ & $82.71 \pm 15.33$ & NS \\
\hline $\mathrm{Pa}, \mathrm{CO}_{2} \mathrm{mmHg}$ & $49.76 \pm 11.58$ & $48.04 \pm 8.53$ & $47.41 \pm 10.81$ & $47.91 \pm 10.12$ & NS \\
\hline $\mathrm{Pa}, \mathrm{O}_{2} / \mathrm{FI}, \mathrm{O}_{2}$ & $235 \pm 28$ & $240 \pm 18$ & $241 \pm 36$ & $226 \pm 22$ & NS \\
\hline
\end{tabular}

Data are presented as mean \pm SD. P-value for one-way analysis of variance test. $P$ a, $\mathrm{CO}_{2}$ : partial pressure of arterial carbon dioxide; $P$ a, $\mathrm{O}_{2}$ : partial pressure of arterial oxygen; $\mathrm{FI}, \mathrm{O}_{2}$ : fractional concentration of oxygen; NS: nonsignificant. $\mathrm{kPa}=\mathrm{mmHg} \times 0.133$. 
Table 3. - Data of breathing pattern and respiratory muscle function during the different trials

\begin{tabular}{|c|c|c|c|c|c|}
\hline & \multirow[t]{2}{*}{ SB } & \multicolumn{4}{|c|}{ Pressurisation rate } \\
\hline & & $30 \mathrm{cmH}_{2} \mathrm{O} \cdot \mathrm{s}^{-1}$ & $80 \mathrm{cmH}_{2} \mathrm{O} \cdot \mathrm{s}^{-1}$ & $120 \mathrm{cmH}_{2} \mathrm{O} \cdot \mathrm{s}^{-1}$ & $200 \mathrm{cmH}_{2} \mathrm{O} \cdot \mathrm{s}^{-1}$ \\
\hline $\mathrm{RR} b \cdot \mathrm{min}^{-1}$ & $19.55 \pm 4.35^{*}$ & $16.85 \pm 5.58$ & $16.9 \pm 4.88$ & $17.4 \pm 4.32$ & $16.43 \pm 4.7$ \\
\hline$V$ Texp mL & $355 \pm 119.2^{\#}$ & $454 \pm 215$ & $446 \pm 199$ & $475 \pm 228$ & $458 \pm 198$ \\
\hline Peak flow $\mathrm{L} \cdot \mathrm{s}^{-1}$ & $0.61+0.29$ & $0.72 \pm 0.25$ & $0.74 \pm 0.35$ & $0.83 \pm 0.32$ & $1.08 \pm 0.38^{\bullet}$ \\
\hline$t \mathrm{I} \mathrm{s}$ & $1.16 \pm 0.23 *$ & $1.35 \pm 0.17$ & $1.36 \pm 0.31$ & $1.27 \pm 0.24$ & $1.23 \pm 0.25$ \\
\hline$t$ tot $\mathrm{s}$ & $3.22 \pm 0.72 *$ & $3.56 \pm 1.12$ & $3.55 \pm 1.10$ & $3.44 \pm 1.02$ & $3.65 \pm 1.52$ \\
\hline te $\mathrm{s}$ & $2.05 \pm 0.57$ & $2.21 \pm 0.96$ & $2.19 \pm 0.89$ & $2.17 \pm 0.95$ & $2.42 \pm 1.49$ \\
\hline$t \mathrm{in} / t \operatorname{Ivent} \%$ & NA & $81.12 \pm 30.50$ & $72.28 \pm 29.53$ & $77.7 \pm 33.17$ & $64.92 \pm 34.20^{+}$ \\
\hline$P$ di tidal $\mathrm{cmH}_{2} \mathrm{O}$ & $9.1+4.6^{\S}$ & $6.8+3.8$ & $5.7+3.2$ & $5.5+3.2$ & $4.2+3.1^{f}$ \\
\hline PT $P \mathrm{di} \cdot \mathrm{b}^{-1} \mathrm{cmH}_{2} \mathrm{O} \cdot \mathrm{s}^{-1}$ & $11.1+5.5^{\S}$ & $8.4+4.9$ & $6.8+3.8$ & $6.6+4.0 * *$ & $5.0+3.4^{\# \#}$ \\
\hline $\mathrm{PTPdi} \cdot \mathrm{cmH}_{2} \mathrm{O} \cdot \mathrm{s}^{-1} \cdot \mathrm{min}^{-1}$ & $206.1+97.0^{\S}$ & $135.5+77.5$ & $111.3+60.8$ & $108.8+52.3$ & $79.4+42.2^{\text {ศศ }}$ \\
\hline$P$ ga exp rise $\mathrm{cmH}_{2} \mathrm{O}$ & $1.26 \pm 0.92$ & $1.30 \pm 1.02$ & $0.8 \pm 0.99$ & $1.30 \pm 1.13$ & $0.9 \pm 1.2$ \\
\hline PEEPi,dyn $\mathrm{cmH}_{2} \mathrm{O}$ & $2.8 \pm 1.6^{++}$ & $2.36 \pm 1.61$ & $2.53 \pm 1.73$ & $2.09 \pm 1.8$ & $2.09 \pm 1.8$ \\
\hline PTPoes $\cdot \mathrm{cmH}_{2} \mathrm{O} \cdot \mathrm{s}^{-1} \cdot \mathrm{min}^{-1}$ & $203.3 \pm 88.1^{\#}$ & $115.54 \pm 63.78$ & $97.69 \pm 54.75$ & $93.62 \pm 45.16$ & $68.08 \pm 42.7^{\oplus \uparrow}$ \\
\hline
\end{tabular}

Data are presented as mean \pm SD or mean $+\mathrm{SD}$. SB: spontaneous breathing; $\mathrm{RR} b \cdot \mathrm{min}^{-1}$ : respiratory rate breaths per minute; $V$ Texp: expiratory tidal volume; peak flow: peak inspiratory flow; $t \mathrm{I}$ : inspiratory time; $t$ tot: total respiratory time; $t$ : expiratory time; $t$ in/ $t$ Ivent: ratio neural inspiratory time/ mechanical inspiratory time; Pdi: transdiaphragmatic pressure; PTPdi $\cdot^{-1}$ : pressure time product of the diaphragm per breath; $P$ ga exp rise: expiratory muscle activity; PEEPi,dyn: dynamic intrinsic positive end-expiratory pressure; PTPoes $\cdot \mathrm{min}^{-1}$ : pressure time product of the inspiratory muscle. *: $\mathrm{p}<0.05$ between SB and $80 \mathrm{cmH}_{2} \mathrm{O} \cdot \mathrm{s}^{-1}$; ${ }^{*}: \mathrm{p}<0.01$ between SB and all noninvasive ventilation (NIV) trials; ${ }^{\natural}: \mathrm{p}<0.001$ between 200 and SB, $30 \mathrm{cmH}_{2} \mathrm{O} \cdot \mathrm{s}^{-1} ;{ }^{+}: \mathrm{p}<0.05$ between 200 and $30 \mathrm{cmH}_{2} \mathrm{O} \cdot \mathrm{s}^{-1} ;{ }^{\S}: \mathrm{p}<0.001$ between SB and all NIV trials; ${ }^{f}: \mathrm{p}<0.01$ between 200 and $30,80,120 \mathrm{cmH}_{2} \mathrm{O} \cdot \mathrm{s}^{-1}$; **: $\mathrm{p}<0.01$ between 120 and $30 \mathrm{cmH}_{2} \mathrm{O} \cdot \mathrm{s}^{-1}$; \#\#: $\mathrm{p}<0.001$ between 200 and $30,80 \mathrm{cmH}_{2} \mathrm{O} \cdot \mathrm{s}^{-1} ;{ }^{* \uparrow}: \mathrm{p}<0.001$ between 200 and $30 \mathrm{cmH}_{2} \mathrm{O} \cdot \mathrm{s}^{-1} ;{ }^{++}: \mathrm{p}<0.05$ between $\mathrm{SB}$ and $200 \mathrm{cmH}_{2} \mathrm{O} \cdot \mathrm{s}^{-1}$.

\section{Tolerance to ventilation and air leaks}

In a physiological study performed in stable, not hypercapnic COPD patients ventilated in assisted-control mode when the ventilator inflation time was shortened by increasing flow, respiratory frequency increased but so did the time available for exhalation, with a small but significant decrease in intrinsic positive end-expiratory pressure and inspiratory effort. Thus, these ventilatory settings, aimed at reducing inflation time (i.e. increasing the pressurisation rate), could be clinically useful [22].

During invasive PSV, a high initial flow rate was also shown to decrease the work of breathing and mouth occlusion pressure after 100 milliseconds without causing major alterations in breathing pattern and gas exchange, so that the investigators concluded that it was logical the use a high inspiratory flow or a very fast pressurisation rate to ventilate these patients in order to minimise the work of breathing [11, $12]$.

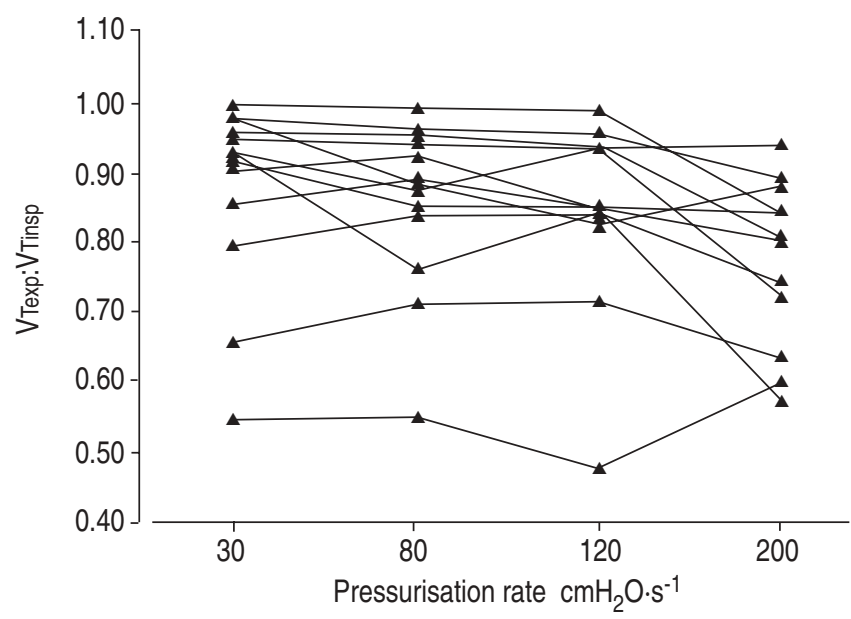

Fig. 2.-Amount of air leaks, as assessed by the ratio between expiratory ( $\left.V_{\text {Texp}}\right)$ and inspiratory tidal volume ( $V_{\text {Tinsp) in the }}$ different runs. $\boldsymbol{\Delta}$ : individual patients.
The objectives of mechanical ventilation are to provide adequate oxygenation, correct acidosis and reduce the work of breathing [23]. There is now solid evidence that NIV should be the first line of treatment for moderate-to-severe acute hypercapnic respiratory failure [24]. It has also been shown that for the same level of inspiratory support, noninvasive PSV is physiologically and clinically similar to PSV delivered through an endotracheal tube [25]. However, these results are only achieved if NIV is set properly and the patient's acceptance and tolerance of the procedure are optimal. Several clinical studies have reported that lack of compliance to ventilation is one of the major causes of failure in both acute hypercapnic and pure hypoxic respiratory failure [26-28].

One of the factors affecting compliance to NIV is probably the presence of air leaks. A large, multicentre survey recently demonstrated that air leaks were significantly more frequent among the patients in whom ventilation failed [5]. Air leaks during noninvasive continuous airway pressure may lead to high unidirectional airflow, which causes a large increase in nasal resistance [29], so that the likelihood of success, especially when NIV is chronically administered, may be lower.

The current study clearly shows that setting the ventilator with the fastest pressurisation rate decreased the acceptance by the patients and that the air leaks increased. Since the inspiratory mechanical time, calculated on the flow trace, was not statistically different in the various runs, it may be predicted that the very rapid achievement of the preset inspiratory plateau pressure would lead to a higher $V \mathrm{~T}$, while this was not the case because of the $20 \%$ difference between the inspired and expired $V$ Ts. Nevertheless, it is worth noting that during the different runs the patients were strictly supervised by a respiratory therapist, and that great attention was taken to minimise the problem of leaks. It is likely that once this direct and constant checking is no longer present, the $V \mathrm{~T}$ could decrease further. From a clinical point of view massive leaks may be responsible not only for poor tolerance but also for potential unbalance between the patient and the ventilator, especially when using ICU or home-care ventilator not specifically designed to compensate for air leaks. In the present study the authors used a so-called previous generation ventilator that has been shown to underperform compared with the new generation ventilators [30], so that the results 


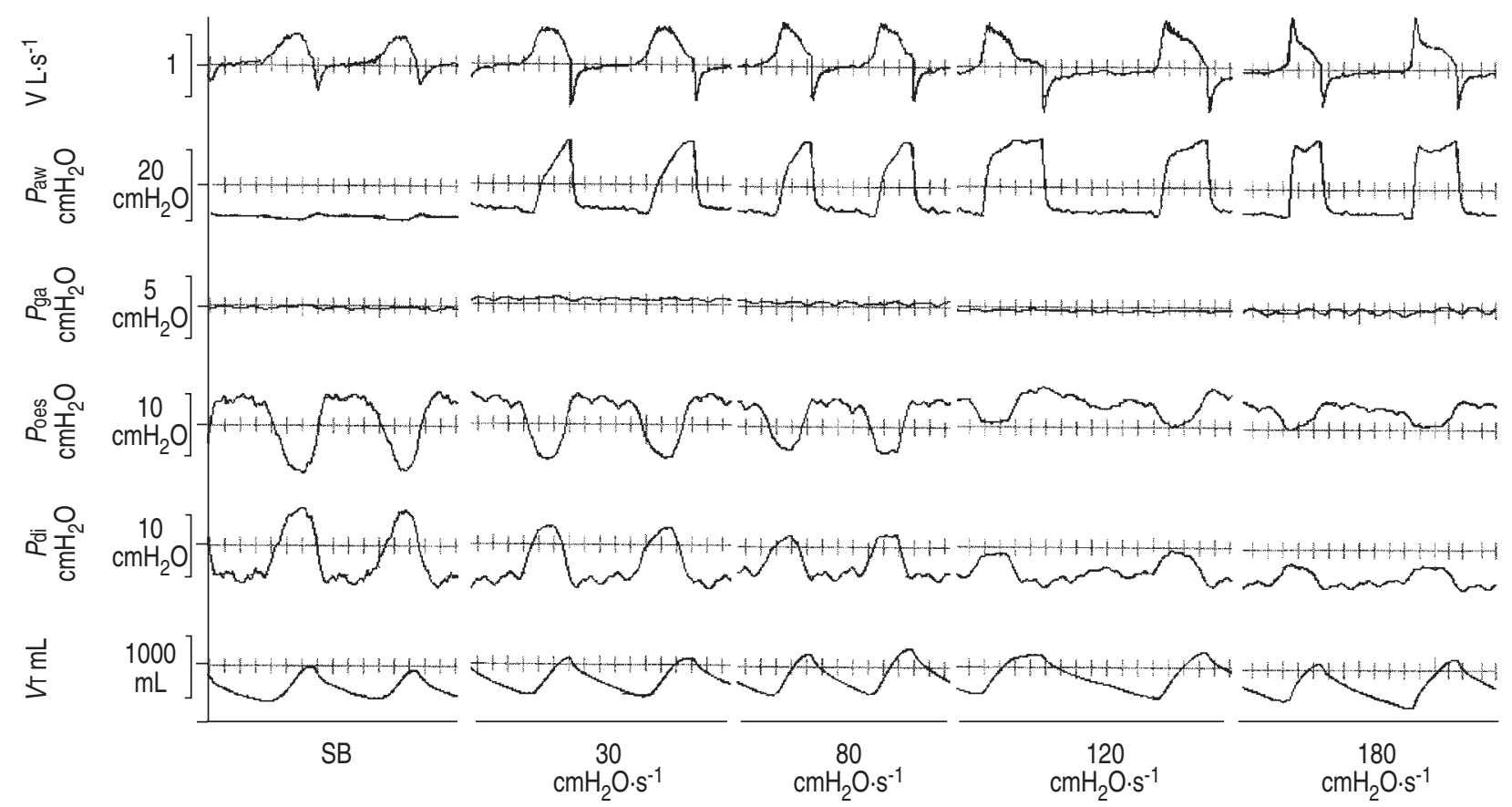

Fig. 3. - Representative traces from a typical patient during the different runs. $V$ : flow; $P$ aw: pressure at the airway opening; $P$ ga: gastric pressure; $P$ oes: oesophageal pressure; $P$ di: transdiaphragmatic pressure; $V$ T: tidal volume; SB: spontaneous breathing.

from the current study cannot necessarily be extrapolated to all the ventilators available. Nonetheless, patient/ventilator mismatching [14] was not observed in the current study at this very high pressurisation rate. It was shown in a bench study that only very massive leaks around the mask (i.e. $>50 \%$ of $V \mathrm{~T})$ were associated, for an inspiratory pressure level of $16 \mathrm{cmH}_{2} \mathrm{O}$, with a failure of the inspiratory flow delivered by the ventilator to reach the expiratory trigger threshold [31]. The tolerance to ventilation was not influenced by the level of inspiratory support required by the patients, since the authors were unable to find any statistical correlation between the PSV level and the pressurisation rate that provided the best comfort.

\section{Diaphragm function and breathing pattern}

This study has confirmed most of the results obtained during invasive ventilation. The pioneering studies were conducted on groups of heterogeneous patients, with no measurements of respiratory mechanics $[9,10]$. More recently, BONMARCHAND and coworkers $[11,12]$ demonstrated that a fast pressurisation rate in COPD patients requiring invasive mechanical ventilation decreased the work of breathing, but not the level of dynamic PEEPi.

The PTPdi is an index of diaphragm oxygen consumption and depends on the time of inspiration and the tidal $P$ di generated during each inspiration [1]. Since the different pressurisation rate in the current study did not significantly influence the respiratory timing, the increase in the metabolic consumption was presumably due to the use of a higher portion of $P$ di. It is rather surprising that the $t \mathrm{I}$ was not significantly shorter with the faster pressurisation rate, and these findings are in contrast with data from most of the studies performed using a pressure assisted mode. The gold standard for evaluating respiratory timing is the respiratory muscle electromyogram (EMG), however for clinical use it is conventionally calculated on the flow trace. From among the surrogate methods of estimation, the bias errors are least when the neural $t \mathrm{I}$ is taken from the Poes trace [17]. The $t \mathrm{I} /$ $t$ Ivent ratio was significantly shorter with the highest pressurisation rate, so that the reduction in PTPdi was probably due to the shorter contraction time. A reduction in the inspiratory effort may also occur during a high pressurisation rate, since this may help to compensate for time-constant dyshomogeneity likely to be present in decompensated COPD patients [22].

It has also been shown that at high levels of PSV many COPD patients show expiratory muscle activation during the inflation phase [32], indicating that the patient may be fighting the ventilator. In the present study this recruitment was

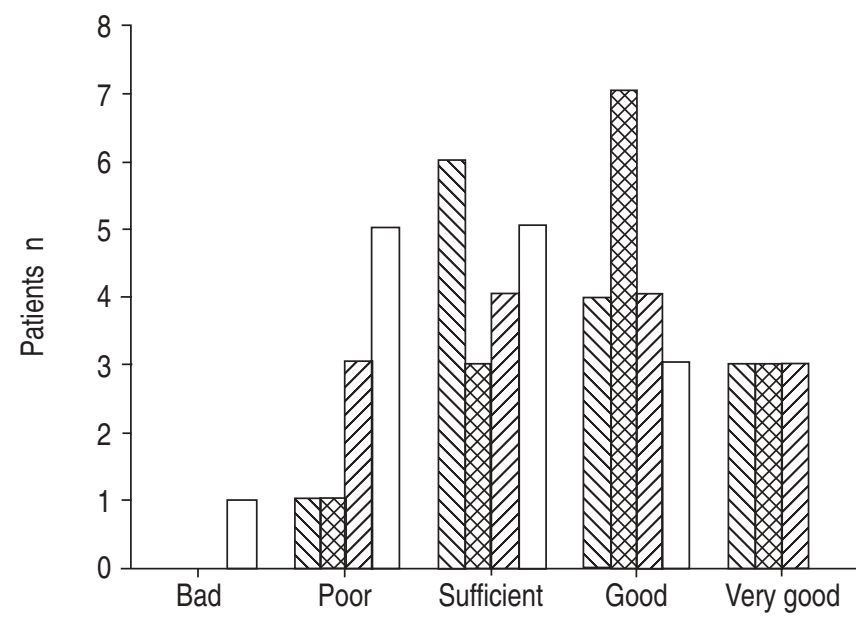

Fig. 4. - Proportion of tolerance score for each pressurisation rate. $\mathbb{\$}$ : $30 \mathrm{cmH}_{2} \mathrm{O} \cdot \mathrm{s}^{-1} ; \mathbf{t}: 80 \mathrm{cmH}_{2} \mathrm{O} \cdot \mathrm{s}^{-1} ; \mathbb{Z}: 120 \mathrm{cmH}_{2} \mathrm{O} \cdot \mathrm{s}^{-1} ; \square: 200 \mathrm{cmH}_{2} \mathrm{O} \cdot \mathrm{s}^{-1}$. 
recorded by the so-called expiratory increase in $P$ ga, which has been shown to correlate with transversus abdominis EMG activity [17]. Most of the patients showed minimal expiratory muscle activation even at the highest pressurisation rate, and this is in contrast with some previous studies $[18,19$, 33]. However, these studies were performed in selected patients who exhibited clinically obvious abdominal muscle activity [19, 33], and normal subjects [18] in whom airflow limitation was induced using a Starling resistor. The current study was performed in a general unselected population of COPD patients, in whom the values of $P$ ga expired rise is likely to be lower, since the patients in the current study were already recovering from the episode of acute respiratory failure.

\section{Clinical implication}

As previously discussed the main goals of mechanical ventilation are to improve gas exchange and reduce the work of breathing [23]. Arterial blood gases were found to be similar with all the settings, and this may be due to the relatively short period of each trial, while the inspiratory effort was reduced most significantly by the highest pressurisation rate.

Although the current study was performed in patients recovering from an acute exacerbation of COPD, the results may be of greater interest for the chronic situation in which the respiratory pattern is quite similar to that observed in the present investigation. In the first period of acute respiratory failure, $t \mathrm{I}$ is usually much shorter and inspiratory flow higher, so that it is likely that the patients may need faster pressurisation rates. In the recovery phase the patients may have less respiratory demand, and therefore a reduction in the pressurisation rate may be more physiological, in order to improve compliance and avoid air leaks.

Many new ventilators are now designed to allow the clinician to set the cycle of criteria at different percentages of the peak flow, while the ventilator used in the current study had a fixed cycling criterion at $5 \mathrm{~L} \cdot \mathrm{m}^{-1}$. Therefore, it is possible that different settings of the expiratory cycling for the same pressurisation rate could influence the physiological variables measured in this study.

In conclusion, in this physiological study of severe chronic obstructive pulmonary disease patients recovering from a severe episode of acute hypercapnic respiratory failure necessitating noninvasive pressure support ventilation, a very high pressurisation rate (i.e. $200 \mathrm{cmH}_{2} \mathrm{O} \cdot \mathrm{s}^{-1}$ ) is associated with increased air leakage and a poor tolerance of ventilation, despite the diaphragmatic effort being reduced. Therefore, the individual titration should be targeted to achieve a good tolerance and minimise the air leaks, keeping a relatively high pressurisation rate. Further studies are needed to assess the influence of different cycle off criteria at different pressurisation rates.

\footnotetext{
Acknowledgements. The authors wish to thank R. Stenner for kindly reviewing the manuscript and G. Butera for useful statistical advice.
}

\section{References}

1. Sassoon CS, Lodia $\mathrm{R}$, Rheeman $\mathrm{CH}$, et al. Inspiratory muscle work of breathing during flow-by, demand-flow, and continuous-flow systems in patients with chronic obstructive pulmonary disease. Am Rev Respir Dis 1992; 145: 1219-1222.

2. Marini J, Capps J, Culver BH. The inspiratory work of breathing during assisted mechanical ventilation. Chest 1985 ; 87: 612-618.

3. Georgopoulos D, Mitrouska I, Bshouty Z, et al. Effects of breathing route, temperature and volume of inspired gas, and airway anaesthesia on the response of respiratory output to varying inspiratory flow. Am J Respir Crit Care Med 1996; 153: $168-175$.

4. Puddy A, Younes M. Effects of inspiratory flow rate on respiratory output in normal subjects. Am Rev Respir Dis 1992; 146: 787-789.

5. Carlucci A, Richard JC, Wysocki M, et al. Noninvasive versus conventional mechanical ventilation. An epidemiologic survey. Am J Respir Crit Care Med 2001; 163: 874-880.

6. Corne S, Gillespie D, Roberts D, et al. Effect of inspiratory flow rate on respiratory rate in intubated patients. $A m J$ Respir Crit Care Med 1997; 156: 304-309.

7. Fernandez R, Mendez M, Younes M. Effect of ventilator flow rate on respiratory timing in normal subjects. $\mathrm{Am}$ J Respir Crit Care Med 1999; 159: 710-719.

8. Kondili E, Prinianakis G, Anastasaki M, et al. Acute effects of ventilatory settings on respiratory motor output in patients with acute lung injury. Intensive Care Med 2001; 27: 1147-1157.

9. Branson RD, Campbell RS, Davis K, et al. Altering flow rate during maximum pressure support ventilation: effects on cardiopulmonary function. Respir Care 1990; 35: 1056-1064.

10. MacIntyre NR, Ho LI. Effects of initial flow rate and breath termination criteria on pressure support ventilation. Chest 1991; 99: 134-138.

11. Bonmarchand $\mathrm{G}$, Chevron $\mathrm{V}$, Chopin $\mathrm{C}$, et al. Increased initial flow rate reduces inspiratory work of breathing during pressure support ventilation in patients with exacerbation of chronic obstructive disease. Intensive Care Med 1996; 22: 1147-1154.

12. Bonmarchand G, Chevron V, Menard J, et al. Effects of pressure ramp slope on the work of breathing during pressure support ventilation in restrictive patients. Crit Care Med 1999; 27: 715-722.

13. ATS Standards for the diagnosis and care of patients with chronic obstructive pulmonary disease. Am J Respir Crit Care Med 1995; 152: 77-120.

14. Nava S, Bruschi C, Rubini F, et al. Respiratory response and inspiratory effort during pressure support ventilation in COPD patients. Intensive Care Med 1995; 21: 871-879.

15. Jaber S, Carlucci A, Boussarsar M, et al. Noninvasive ventilation with helium-oxygen in acute exacerbations of chronic obstructive pulmonary disease. Am J Respir Crit Care Med 2000; 161: 1191-1200.

16. Baydur A, Behrakis PK, Zin WA, et al. A simple method for assessing the validity of the esophageal balloon technique. Am Rev Respir Dis 1982; 126: 788-791.

17. Parthasarathy S, Jubran A, Tobin M. Assessment of neural inspiratory time in ventilator-supported patients. Am J Respir Crit Care Med 2000; 162: 546-552.

18. Parthasarathy S, Jubran A, Tobin M. Cycling of inspiratory and expiratory muscle groups with the ventilator in airflow limitation. Am J Respir Crit Care Med 1998; 158: 1471-1478.

19. Lessard MR, Lofaso F, Brochard L. Expiratory muscle activity increases intrinsic positive end-expiratory pressure independently of dynamic hyperinflation in mechanically ventilated patients. Am J Respir Crit Care Med 1995; 151: 562-569.

20. Appendini L, Purro A, Gudjonsdottir M, et al. Partitioning of inspiratory muscle workload and pressure assistance in ventilator-dependent COPD patients. Am J Respir Crit Care Med 1996; 154: 1301-1309.

21. Navalesi P, Fanfulla F, Frigerio $\mathrm{P}$, et al. Physiologic evaluation of noninvasive mechanical ventilation delivered with three types of mask in patients with chronic hypercapnic respiratory failure. Crit Care Med 2000; 28: 1785-1790.

22. Laghi F, Segal J, Choe WK, et al. Effect of imposed inflation time on respiratory frequency and hyperinflation in patients 
with chronic obstructive pulmonary disease. Am J Respir Crit Care Med 2001; 163: 1365-1370.

23. Tobin MJ. Advances in mechanical ventilation. $N$ Engl J Med 2001; 344: 1986-1996.

24. International Consensus Conferences in Intensive Care Medicine: noninvasive positive pressure ventilation in acute respiratory failure. Am J Respir Crit Care Med 2001; 163: 283-291.

25. Vitacca M, Ambrosino N, Clini E, et al. Physiological response to pressure support ventilation delivered before and after extubation in patients not capable of totally spontaneous autonomous breathing. Am J Respir Crit Care Med 2001; 164: 638-641.

26. Antonelli M, Conti G, Moro ML, et al. Predictors of failure of noninvasive positive pressure ventilation in patients with acute hypoxemic respiratory failure: a multi-center study. Intensive Care Med 2001; 27: 1718-1728.

27. Ambrosino N, Foglio K, Rubini F, et al. Noninvasive mechanical ventilation in acute respiratory failure due to chronic obstructive pulmonary disease: correlates for success. Thorax 1995; 50: 755-757.

28. Moretti M, Cilione C, Tampieri A, et al. Incidence and causes of noninvasive mechanical ventilation failure after initial success. Thorax 2000; 55: 819-825.

29. Richards GN, Cistulli PA, Ungar RG, et al. Mouth leak with nasal continuous positive airway pressure increases nasal airway resistance. Am J Respir Crit Care Med 1996; 154: 182-186.

30. Richard JC, Carlucci A, Breton L, et al. Bench testing of pressure support ventilation with three different generations of ventilators. Intensive Care Med 2002; 28: 10491057.

31. Schettino GP, Tucci MR, Sousa R, et al. Mask mechanics and leak dynamics during noninvasive pressure support ventilation: a bench study. Intensive Care Med 2001; 27: $1887-1891$.

32. Jubran A, Van de Graaff WB, Tobin MJ. Variability of patient-ventilator interaction with pressure support ventilation in patients with chronic obstructive pulmonary disease. Am J Respir Crit Care Med 1995; 152: 129-136.

33. Zakynthinos SG, Vassilakopoulos T, Zakynthinos E, et al. Correcting static intrinsic end-expiratory pressure for expiratory muscle contraction. Validation of a new method. Am J Respir Crit Care Med 1999; 160: 785-790. 